\title{
Freshwater Microplastics: Challenges for Regulation and Management
}

\author{
Nicole Brennholt, Maren Heß, and Georg Reifferscheid
}

\begin{abstract}
The accumulation of plastic debris in aquatic environments is one of the major but least studied human pressures on aquatic ecosystems. Besides the general waste burden in waterbodies, (micro)plastic debris gives rise to ecological and social problems. Related to marine ecosystems, these problems are already in the center of interest of science, policy, and public. The United Nations Environment Programme, for instance, drafted a joint report on "marine plastic debris and microplastics," and the European Community included the issue into the European Marine Strategy Framework Directive, descriptor 10 "marine litter."

However, (micro)plastic litter in freshwater systems is not yet explicitly addressed in the respective regulations, although the issue is relevant for many international and national policy instruments and initiatives. Many conventions, agreements, regulations, strategies, action plans, programs, and guidelines refer to "all wastes" in general. This should also concern (micro)plastic waste.

This chapter provides an overview of the regulatory instruments developed at different levels to address freshwater (micro)plastic litter. Beyond that, specific management options and measures that are either compulsory or voluntary are presented. Nevertheless, only few options have been realized so far. Reasons are numerous, first and foremost the lack of consensus on the definition of microplastics.
\end{abstract}

Nicole Brennholt and Maren Heß contributed equally to this work.

N. Brennholt $(\triangle)$ and G. Reifferscheid

Department Biochemistry, Ecotoxicology, Federal Institute for Hydrology, Am Mainzer Tor 1, 56068, Koblenz, Germany

e-mail: brennholt@bafg.de

M. Heß (ه)

Department Water Management, Water Protection, North Rhine Westphalia State Agency for Nature, Environment and Consumer Protection, Postfach 101052, 45610, Recklinghausen, Germany 
The complexity of these particulate stressors with very heterogeneous physicochemical characteristics poses new challenges for regulation and management. We highlight the most important questions from the perspective of freshwater monitoring. Furthermore, we discuss a possible adaption of existing environmental policy instruments and potential management options for single categories of (micro)plastics.

Keywords Environmental plastics, Microplastics definition, Nationalinternational, Policy instruments, Science-policy interface

\section{Introduction}

"Microplastics" (MPs) are a topic of discussion in all types of media and are one of the environmental issues also strongly debated by the public (see [1]). A questionnaire sent to the representatives responsible for water monitoring and management in Europe revealed that around 50\% of the European population is discussing about MPs and its potential harm to the environment and human health [2]. Hence, the public expects policy-makers to tackle the problem and to manage it as soon as possible.

In fact, awareness about this issue is increasing in policy. Some of the most important and worldwide acting international and intergovernmental bodies are debating about the global problem of environmental plastics (e.g., United Nations, G7, World Bank, World Economic Forum, etc.). Beyond that, the (micro)plastic issue is already addressed in a few regulations and policy instruments on international and national level (see Sects. 2.1 and 2.2). As most environmental MPs result from incorrect disposed and fragmented plastic litter (see [3]), the management of MPs is closely related to a variety of policy areas. Additionally, regulatory responsibilities can change along the product life of a single plastic product and include plastic production and product design, trade and consumer behavior, recycling and waste management (summarized as "land-based policies"), as well as wastewater management and water protection ("water-based policies"). Hence, the regulation of plastics is already considered in several directives, guidelines, agreements, etc. addressing the application of plastic products, starting with regulations on plastic monomers and additives (e.g., REACH; ${ }^{1}$ see Sect. 2.2.3). The use of plastic products is especially regulated in sensible application fields, e.g., food packaging. Recently, management strategies increasingly aim at plastics that either are not needed for the function of a product or do not benefit the user or can easily be replaced by other materials - e.g., carrier bags (see Sect. 2.2.2) or MPs in personal care products (see Sect. 2.3). Various directives address the recycling or disposal of plastics at the end of product life (see Sect. 2.2.2).

Given an efficient plastic management, including waste and wastewater control, plastics should not enter environmental systems. However, they do. Problematically, environmental plastics are outside the intended product life.

${ }^{1}$ Regulation concerning the Registration, Evaluation, Authorisation and Restriction of Chemicals. 
While regulatory measures can be clearly addressed to one stakeholder at a certain stage of product life (e.g., producer, manufacturer, consumer, waste manager), it is more difficult to identify the correct addressee for plastics already released to the environment. So far, due to the complexity of this issue, it is not clear which (policy) areas have to act first, which concepts would be necessary, and what requirements are needed to promote actions beyond those already initiated.

With regard to aquatic environments, (micro)plastics are mainly considered by marine science and policy and, for instance, implemented into the European Marine Strategy Framework Directive (MSFD, [4], descriptor 10 "marine litter"). A comprehensive overview on regulation and management of marine (plastic) litter is provided by Chen [5]. However, it is assumed that approximately $80 \%$ of marine debris is land based [6], even though there is a lack of available quantitative evidence supporting this statement. Rivers are one of the entry pathways for (micro)plastics into marine ecosystems. However, the plastic issue is not explicitly addressed in any regulation regarding freshwater environments so far. In contrast to the MSFD, the 8 years older European Water Framework Directive (WFD, [7]) does not include the issue of plastic pollution.

The management of MPs in aquatic systems is even more complex than the regulation of macroplastic litter. Many questions need to be answered, starting with a commonly accepted definition of MPs. Knowledge gaps about sources, transport pathways, and volumes and the environmental fate of the small particles with their heterogeneous characteristics have to be filled, not at least to define adequate methods for a standardized freshwater monitoring of MPs. The adaption of exposure and hazard assessment to evaluate the risk of freshwater MPs as particulate stressors is one of the major challenges for regulation and management. Currently, essential yet unanswered questions refer to the ecological impacts of plastics on today's environment, let alone their long-term consequences.

Notwithstanding, the issue of (micro)plastic pollution in freshwater environments is one of the major but least studied human pressures on aquatic ecosystems, and further research is required on this issue. Nevertheless, there are many indications for adverse environmental impacts that should lead to preventive measures. As stated in Article 191 of the Lisbon Treaty [8], the European Community policy on the environment "[ . . ] shall aim at a high level of protection taking into account the diversity of situations in the various regions of the Union. It shall be based on the precautionary principle and on the principles that preventive action should be taken, that environmental damage should as a priority be rectified at source and that the polluter should pay." Therefore, regulation and management should deal with the issue of freshwater (micro)plastics.

This chapter provides a rough overview of the existing regulatory instruments developed at international and national levels which address or at least touch the topic of freshwater (micro)plastics. It does not intend to develop new regulatory approaches dealing with the issue but highlights challenges for regulation and management. Despite the regulation of (micro)plastics being already addressed in a few initiatives, it is still far from a comprehensive management. Reasons might be various as (micro)plastics pose new challenges for freshwater monitoring and regulation. This will be discussed in the third section of this chapter. A compilation 
of the requirements concerning future standards and guidelines is given from the perspective of specialized authorities conducting monitoring programs on regional, state, and national level (Germany).

\section{Regulatory and Policy Instruments}

This section provides a brief overview of the current regulatory and policy instruments developed at international, regional, and national levels associated with the issue of (micro)plastics in freshwater systems (Fig. 1). National policy instruments apply only to a particular country, whereas regional instruments tackle certain problems within a specific geographical region, e.g., Europe. International regulation and regional agreements, for instance, are transposed into national legislation, so that similar texts can be found in the instruments at the national level.

The interfaces with the legislation are various: direct links are more likely in marine regulation, whereas freshwater (micro)plastics are not explicitly addressed in regulation so far, although this issue is related, for instance, to many European directives. Within this section, an attempt is being made to demonstrate this link. If possible, regulatory strategies for the integration of (micro)plastics in existing legal instruments are proposed. However, the focus is on European regulatory and policy instruments.

\section{International}

e.g. conventions, agreements, regulations, strategies, action plans, programs and guidelines by United Nations, G7, World Economic Forum, World Bank, etc.

\begin{tabular}{|l|l|c|c|c|}
\hline & Regional \\
\hline Lisbon Treaty & REACH* & $\begin{array}{c}\text { Marine Strategy } \\
\text { Framework } \\
\text { Directive }\end{array}$ & $\begin{array}{c}\text { Framework } \\
\text { Directive on } \\
\text { Waste }\end{array}$ & etc. \\
\hline
\end{tabular}

\begin{tabular}{|l|c|c|c|c|c|}
\hline \multicolumn{5}{|c|}{ National } \\
\hline \multirow{2}{*}{ Littering Acts } & $\begin{array}{c}\text { Carrier Bag } \\
\text { Charge }\end{array}$ & $\begin{array}{c}\text { Deposit \& } \\
\text { Return } \\
\text { Systems }\end{array}$ & $\begin{array}{c}\text { Waste } \\
\text { Management } \\
\text { Plans }\end{array}$ & $\begin{array}{c}\text { Packaging } \\
\text { Regulations }\end{array}$ & etc. \\
\hline
\end{tabular}

Fig. 1 Levels of regulatory and policy instruments and initiatives for the regulation, assessment, and management of freshwater (micro)plastic litter. * REACH Regulation concerning the Registration, Evaluation, Authorisation and Restriction of Chemicals 


\subsection{International-Level Instruments and Initiatives}

International regulation, namely, conventions, agreements, regulations, strategies, action plans, programs, and guidelines, is transposed into regional or national instruments. This is usually done through regional agreements or national legislations so that similar texts can also be found in the instruments at the regional or national level. International instruments apply to the signatory countries and include different geographical regions worldwide.

\section{United Nations (UN)}

Based on the Millennium Development Goals, the UN General Assembly adopted the resolution no. A /RES/70/1 "Transforming Our World: The 2030 Agenda for Sustainable Development" on 25 September 2015 [9]. Within this agenda, 17 sustainable development goals with 169 associated targets are announced. Goal 12 "Ensure sustainable consumption and production patterns" includes the following target 12.4: "By 2020, achieve the environmentally sound management of chemicals and all wastes throughout their life cycle, in accordance with agreed international frameworks, and significantly reduce their release to air, water and soil in order to minimize their adverse impacts on human health and the environment" [9, p. 22]. Furthermore, the waste generation shall be substantially reduced by 2030 through prevention, reduction, recycling, and reuse (target 12.5). Although these targets refer to "all wastes" in general, they also cover plastic wastes. The new goals and targets addressed in the agenda have come into effect on 1 January 2016 and will guide the decisions of the member states over the next 15 years. Therefore, the General Assembly "encourages all member states to develop as soon as practicable ambitious national responses to the overall implementation of this Agenda. These can support the transition to the Sustainable Development Goals and build on existing planning instruments, such as national development and sustainable development strategies, as appropriate" [9, p. 33].

\section{The Group of 7 (G7)}

The Group of 7 (G7) consists of Canada, France, Germany, Italy, Japan, the UK, and the USA. As environmental issues play an important role alongside economics, foreign policy, and security, topics discussed at G7 summits include climate change, sustainable development, resource efficiency, marine pollution, and nuclear safety. In 2015, the G7 discussed options to address plastic pollution in marine environments and "acknowledge that marine litter, in particular plastic litter, poses a global challenge, directly affecting marine and coastal life and ecosystems and potentially also human health" [10, p. 17]. Among others, the G7 countries are aware of the need for worldwide movement to tackle marine pollution. Therefore, they are developing an action plan to combat marine litter, which provides, inter alia, that practical measures to reduce waste from land- and sea-based sources will be implemented. At this point, it becomes apparent that although marine ecosystems are in the center of interest, freshwater systems cannot be neglected. This is also reflected in the G7 action plan to combat marine litter, 
where it is stated that they "support development and implementation of national or regional action plans to reduce waste entering inland and coastal waters and ultimately becoming marine litter, as well as to remove existing waste" [11, p. 9]. The G7 action plan lists the following priority actions to address land-based sources:

- Improving countries' systems for waste management, reducing waste generation, and encouraging reuse and recycling;

- Incorporating waste management activities into international development assistance and investments and supporting the implementation of pilot projects where appropriate;

- Investigating sustainable and cost-effective solutions to reduce and prevent sewage and storm water related waste, including micro plastics entering the marine environment;

- Promoting relevant instruments and incentives to reduce the use of disposable singleuse and other items, which impact the marine environment;

- Encouraging industry to develop sustainable packaging and remove ingredients from products to gain environmental benefits, such as by a voluntary phase-out of microbeads;

- Promoting best practices along the whole plastics manufacturing, and value chain from production to transport, e. g. aiming for zero pellet loss. [11, p. 10]

The G7 points out that existing platforms and tools for cooperation should be used like the Global Programme of Action for the Protection of the Marine Environment from Land-Based Activities (GPA). The GPA "is the only global intergovernmental mechanism directly addressing the connectivity between terrestrial, freshwater, coastal and marine ecosystems. It aims to be a source of conceptual and practical guidance to be drawn upon by national and/or regional authorities for devising and implementing sustained action to prevent, reduce, control and/or eliminate marine degradation from land-based activities" (retrieved 10.11.2016 from http://www.unep.org/gpa/).

The common understanding of the topic "marine litter" and the most important areas of action and approaches by the G7 can indeed be understood as a step toward an intergovernmental effort against marine litter, but considering that there is a huge potential for reduction regarding litter reaching the sea mainly from landbased sources, litter in freshwater systems should also be in the focus and require concrete measures.

\section{World Economic Forum (WEF)}

In January 2016, the World Economic Forum (WEF) published an industry agenda entitled "The New Plastic Economy: Rethinking the Future of Plastics." It states that despite many benefits, the current plastic economy has economic as well as environmental detriments that are becoming more apparent by now: "After a short first-use cycle, $95 \%$ of plastic packaging material value, or \$80-120 billion annually, is lost to the economy. A staggering $32 \%$ of plastic packaging escapes collection systems, generating significant economic costs by reducing the productivity of vital natural systems such as the ocean and clogging urban infrastructure" $[12$, p. 6]. The agenda assesses the up- and downsides of today's plastic packaging emphasizing the need to rethink the current plastic economy. A new and systemic approach and action plan to achieve a better economic and environmental outcome 
are proposed. Thereby, "[t]he circular economy is gaining growing attention as a potential way for our society to increase prosperity, while reducing demands on finite raw materials and minimizing negative externalities" [12, p. 3]. The three main efforts of the New Plastic Economy are to:

1. Create an effective after-use plastics economy by improving the economics and uptake of recycling, reuse and controlled biodegradation for targeted applications. This is the cornerstone of the New Plastics Economy and its first priority, and helps realize the two following ambitions.

2. Drastically reduce leakage of plastics into natural systems (in particular the ocean) and other negative externalities.

3. Decouple plastics from fossil feedstocks by - in addition to reducing cycle losses and dematerializing - exploring and adopting renewably sourced feedstocks. [12, p. 16]

\section{World Bank}

The World Bank's Urban Development and Resilience Unit of the Sustainable Development Network produces the Urban Development Series Knowledge Papers to discuss the challenges of urbanization. Within this series, a global review of solid waste management is given by Hoornweg and Bhanda-Tata [13]. This review comprises global management practices, generation, collection, composition, and disposal of waste and compares these across different regions of the world. Furthermore, they did not only estimate global amounts and trends but also make projections on waste generation and composition for the near future in order for decision-makers to prepare accordingly. Further, they describe practical approaches and a range of policy options for governments that could be applied in most cities to encourage waste management practices that will reduce greenhouse gas emissions. They note that "Poorly managed waste has an enormous impact on health, local and global environment, and economy; improperly managed waste usually results in down-stream costs higher than what it would have cost to manage the waste properly in the first place" [13, p. 11].

In 2015, the World Bank established a Pollution Management and Environmental Health (PMEH) program that covers technical assistance and financing for reducing pollution and improving health for all. Three strategic objectives were formulated to progress toward this goal:

- Help selected countries to significantly reduce air, land, and marine pollution levels and thereby improve environmental health outcomes

- Generate new knowledge and improve our understanding of pollution and its health impacts in urban, rural, and marine areas

- Promote increased awareness of environmental health and pollution issues among policy makers, planners, and other relevant stakeholders in low- and middle-income countries (LMICs) through dissemination of scientific evidence in this area, including but not limited to content generated through this program. [14, p. 6]

One component of the PMEH program activities dealing with integrated solid waste management to reduce land-based pollution in marine environments does clearly refer to plastic litter. It addresses issues such as upstream control of solid waste generation to prevent and reduce downstream impacts, focusing on reducing the inflow of plastic litter into marine environments. 


\subsection{Regional-Level Instruments with Focus on the European Union}

Instruments to tackle the problems concerning freshwater (micro)plastics in the European Union are typically regional agreements, regional programs, legislation, or activities dealing with specific problems of freshwater (micro)plastics. The Lisbon Treaty, which aimed at increasing the consistency and coherence of the EU's external actions, stated in Article 191 that the EU policy on the environment shall contribute to preserve, protect, and improve the quality of the environment, protect human health, utilize natural resources in a prudent and rational way, and promote measures at international level to deal with regional or worldwide environmental problems. In this context, the European directives dealing with various aspects of environmental protection can be seen. In the light of the increasing number of scientific publications dealing with the impacts of (micro)plastics on aquatic environments, especially on aquatic organisms, as well as due to the transboundary dimension of plastic pollution, the EU is called upon to develop appropriate policy strategies. As already mentioned, the "water-based policies" such as water protection (MSFD, WFD) and the "land-based policies" such as waste management, plastic production and product design, circular economy, and REACH are affected or likely to be affected by the issue of (micro)plastic pollution of freshwater systems.

\subsubsection{Water-Based Policy}

The most important directives for the European water policy are the Marine Strategy Framework Directive (MSFD) [4] and the Water Framework Directive (WFD) [7] establishing the legal framework for the protection of European marine and freshwater environments, respectively. Although both aim at implementing a good ecological/environmental status, there is a large discrepancy between them regarding the issue of plastic waste. In the MSFD, waste is defined as one out of 11 qualitative indicators of the good environmental status (descriptor 10 "marine litter"; for further discussion, see [5]), whereas in the WFD, waste is not mentioned. In a possible future revision of the WFD (next review due in 2019), this discrepancy might be clarified.

\section{European Water Framework Directive (WFD)}

The WFD has been enacted in October 2000 by the European Commission and focuses on "maintaining and improving the aquatic environment in the Community [...] ensuring good [water] quality" [7, p. 2]. Therefore, the amount of pollution entering waterways should be minimized, and the objectives for future water protection should be set. "It does not set exact regulations, but gives each country space to fit the national legislation to put it into practice and arranges and coordinates existing European water legislation" [15, p. 80]. In recital 40, it is noted that 
"[w]ith regard to pollution prevention and control, Community water policy should be based on a combined approach using control of pollution at source through the setting of emission limit values and of environmental quality standards" [7, p. 4]. Article 10 describes the combined approach for point and diffuse sources in more detail, "(a) the emission controls based on best available techniques, or (b) the relevant emission limit values, or (c) in the case of diffuse impacts the controls including, as appropriate, best environmental practice" [7, p. 13], and points, in this respect, to further relevant directives.

Even though the 8 years older WFD does not explicitly refer to (micro)plastics or litter in general, Wesch et al. [16] argued that plastic waste is already indirectly integrated in the WFD as it currently stands. In their opinion, litter is broadly associated with relevant quality elements determining the good ecological status of freshwater systems. Consequently, the occurrence of litter, in particular (micro) plastics, could considerably influence the water quality. Furthermore, they point out that a good chemical status of surface waters according to the WFD is achieved when concentrations of listed chemicals (Annex X, WFD) do not exceed the environmental quality standards.

In Article 16, strategies against the pollution of water are mentioned in such a way that "the European Parliament and the Council shall adopt specific measures against pollution of water by individual pollutants or groups of pollutants presenting a significant risk to or via the aquatic environment" [7, p. 17]. Approaches described in Article 16 of the WFD result in a list of priority substances (approved in Annex X). This list registers 45 priority substances or groups of substances, several of which are applied in plastic products such as di (2-ethylhexyl)phthalate, nonylphenol, or octylphenol. As far as priority substances are concerned, the member states are legally obligated to monitor them. However, the measured total concentration of a substance includes all sources of pollution and cannot indicate the plastic-related percentage.

Furthermore, Annex VIII comprised an indicative list of the main pollutants, among others "persistent hydrocarbons and persistent and bioaccumulative organic toxic substances" as well as "substances and preparations, or the breakdown products of such, which have been proved to possess carcinogenic or mutagenic properties or properties which may affect steroidogenic, thyroid, reproduction or other endocrine-related functions in or via the aquatic environment" [7, p. 68]. This might include synthetic polymers and their additives. However, (micro)plastics are not explicitly addressed in the WFD. This discrepancy should be clarified in a possible future revision of the WFD due by 2019, and an assessment system needs to be developed.

\section{Water Protection and Wastewater Treatment Directives}

To protect the environment from the adverse effects of urban wastewater discharges and discharges from certain industrial sectors, the European Urban Waste Water Treatment Directive [17] was adopted in 1991. It concerns the collection, treatment, and discharge of domestic effluent or mixture of domestic and certain industrial 
wastewater (see Annex III of the directive) and/or rainfall water. The issue of (micro)plastic is not included, so that adequate amendments might be needed.

Compared to Europe, the US wastewater regulations established by the Federal Water Pollution Control Act, short Clean Water Act [18], provide the basic structure for regulating discharges of pollutants and regulating quality standards for surface waters. The Clean Water Act refers to regulation of wastewater as well as entry of waste from diffuse sources. Total maximum daily loads of waste are defined aiming at reducing the waste input to freshwater systems. However, it should be noted that, for example, under Californian law, debris less than $5 \mathrm{~mm}$ is not considered litter subject to regulation [15, 19, 20]. Accordingly, freshwater MPs, here too, are currently not considered.

\subsubsection{Land-Based Policy}

\section{Packaging}

The Packaging and Packaging Waste Directive [21] calls on the member states to implement return, collection, and recovery systems. The manufacturers, importers, and distributors are directly responsible for reducing packaging waste as well as for developing their own take-back scheme. The "Green Dot Initiative" covering several European countries, for example, collects, sorts, and recycles used packaging. Furthermore, it encourages giving packaging waste a value while being recovered and/or recycled. Hence, the Packaging and Packaging Waste Directive aims not only at "ensur[ing] the functioning of the internal market and to avoid obstacles to trade and distortion and restriction of competition within the Community" but also at "prevent[ing] any impact [...] on the environment of all Member States as well as of third countries or [...] reduc[ing] such impact, thus providing a high level of environmental protection" [21, p. 3].

The Directive 2004/12/EC of the European Parliament and of the Council of 11 February 2004 amending Directive 94/62/EC on packaging and packaging waste [22] aims to ensure that recovery and recycling of packaging waste should be further increased to reduce its environmental impact. With regard to plastics contained in packaging waste, it sets a minimum recycling target of $22.5 \%$ by weight no later than 31 December 2008, counting exclusively material that is recycled back into plastics. Annex I gives illustrative examples for criteria of "packaging" referred to in Article 3(1) of [21]. Here, among others, plastic carrier bags are mentioned.

\section{Carrier Bags}

Meanwhile, the issue of plastic carrier bags is picked up by another amending directive, known as the Plastic Bags Directive [23]. The Plastic Bags Directive is for the first time considering not only the management of packaging and packaging waste but also its consumption. It was adopted in 2015, and its implementation is currently underway in the member states. It aims at reducing very significantly the use of single-use lightweight plastic carrier bags. The measures to be taken by the 
member states "may involve the use of economic instruments such as pricing, taxes and levies, which have proved particularly effective in reducing the consumption of plastic carrier bags" [23, p. 2]. The original directive on packaging and packaging waste of 1994 [21] aimed at preventing or reducing the impact of packaging and packaging waste on the environment. Even though plastic carrier bags are included in this directive [21], it does not comprise specific measures on the consumption of such plastic bags.

\section{Waste Legislation}

In the present European waste legislation, some strategic elements already exist to tackle the problem of plastic waste in the environment. The Waste Framework Directive [24], for example, relates to issues of product design, life cycle thinking, extended producer responsibility, resource efficiency and conservation, as well as waste prevention through waste operations. This directive aims at "lay[ing] down measures to protect the environment and human health by preventing or reducing the adverse impacts of the generation and management of waste and by reducing overall impacts of resource use and improving the efficiency of such use" [24, p. 6]. It sets general recycling targets for household waste including plastics " [. . .] by 2020 , the preparing for re-use and the recycling of waste materials such as at least paper, metal, plastic and glass from households [...] shall be increased to a minimum of overall $50 \%$ by weight" [24, p. 11]. Furthermore, in Article 4(1), an explicit waste hierarchy is defined as a priority order in waste prevention and management legislation and policy. It gives precedence to waste prevention; reuse and recycling over recovery, including energy/thermal recovery; and disposal. In addition to the Waste Framework Directive [24], other directives [25-28] also set out recovery and recycling targets.

Another key element in waste management is the extended producer responsibility as described in Article 8 of the Waste Framework Directive [24]. Next to this, it introduces the polluter-pays principle as "guiding principle at European and international levels. The waste producer and the waste holder should manage the waste in a way that guarantees a high level of protection of the environment and human health" [24, p. 4]. Furthermore, "[In] accordance with the polluter-pays principle, the costs of waste management shall be borne by the original waste producer or by the current or previous waste holder" [24, p. 12]. The "polluterpays principle" is also mentioned in the directive on environmental liability [29] with regard to the prevention and remedying of environmental damage.

According to the waste management hierarchy as laid out in the Waste Framework Directive [24], disposal of waste is the least preferable option and should be limited to the necessary minimum. If disposed waste needs to be landfilled, it has to be sent to landfills, which comply with the requirements of the directive on the landfill of waste [30]. The main objective of this directive is the prevention and reduction of negative effects on the environment, including freshwaters, from the landfilling of waste by introducing strict technical requirements.

In 2014 the European Commission made a legislative proposal [31], which states that "clear environmental, economic and social benefits would be derived from 
further increasing the targets laid down in Directives 2008/98/EC, 94/62/EC and 1999/31/EC for re-use and recycling of municipal and packaging waste, starting with waste streams which can be easily recycled (e.g. plastics, metals, glass, paper, wood, bio-waste)" [31, p. 9]. With regard to the directive on packaging and packaging waste [21], Article 6 should be amended as follows: "by the end of 2020 , the following minimum targets for preparing for re-use and recycling will be met regarding the following specific materials contained in packaging waste: $45 \%$ of plastic [...] and by the end of 2025, the following minimum targets for preparing for reuse and recycling will be met regarding the following specific materials contained in packaging waste: $60 \%$ of plastic" [31, p. 23]. Concerning the amendment of the directive on the landfill of waste [30], the proposal aims at phasing out landfilling by 2025 for recyclable waste, including plastics, in nonhazardous waste landfills. It is also said that "littering, especially of plastic, has a direct and detrimental impact on the environment and high clean-up costs are an unnecessary economic burden. The introduction of specific measures in waste management plans, financial support from producers within the extended producer responsibility schemes, and proper enforcement from the competent authorities should help eradicate this problem" [31, p. 11].

\section{Circular Economy Package}

The discussion on resource efficiency and waste reduction often refers to a systemic change from a linear to a circular economy model (see [32]). In 2015, the European Commission adopted a Circular Economy Package with five priority sectors, among others plastics. It should "stimulate Europe's transition towards a circular economy [...] where resources are used in a more sustainable way" [33, p. 1]. The proposed actions will contribute to "closing the loop" of product life cycles from production and consumption to waste management and the market for secondary raw materials. Concerning the future work on the circular economy, the European Commission schedules a strategy to incentivize plastic recycling ("plastic circular economy strategy") for the following years [34].

\section{Industrial Emissions Directive}

In general, the Industrial Emissions Directive (IED) [35] aims at preventing, controlling, and reducing the impact of industrial emissions on the environment (air, water, and land) ensuring a high level of protection for the environment taken as a whole. According to this directive, the guiding principle of sustainable production shall be developed further. For this purpose, an integrative approach takes into account not only pollution emissions but also all production processes to reduce the consumption of resources and energy as well as the environmental damage caused by operation and post-closure of an industrial plant. For this, best available techniques have to be applied. In Annex I, categories of industrial activities giving rise to pollution are listed including the production of organic chemicals, such as plastic materials (polymers, synthetic fibers). 


\section{Green Paper on a European Strategy on Plastic Waste in the Environment}

In 2013 the European Commission released a Green Paper on a European Strategy on Plastic Waste in the Environment "to launch a broad reflection on possible responses to the public policy challenges posed by plastic waste," because these particular challenges are not specifically addressed in the EU waste legislation at present despite the growing environmental impact of plastic pollution [36, p. 3]. This Green Paper is the first systematic approach to (micro)plastics in the environment at EU level. It explicitly refers to the problem of (micro)plastics and their fate in the environment and the issue of chemicals in and adsorbed to (micro)plastics as well as examines several policy options to improve the management of plastic waste in Europe. The Green Paper addresses the following policy options (as presented by Clayton, $2016^{2}$ ):

- Application of the waste hierarchy to plastic waste management

- Achievement of targets, plastic recycling, and voluntary initiatives

- Targeting consumer behavior

- Toward more sustainable plastics

- Durability of plastics and plastic products

- Promotion of biodegradable plastics and bio-based plastics

- EU initiatives dealing with marine litter including plastic waste

- International action

Thus, in its Green Paper, the European Commission clearly addressed microplastics as part of the waste legislation focusing on mitigation measures.

\subsubsection{Chemical Regulation: REACH ${ }^{3}$}

For regulating chemical substances, the European REACH regulation [37] has been adopted in 2006. REACH addresses not only the production and use of chemicals but also their potential impacts on both human health and the environment. According to REACH manufacturers, importers and downstream users have to register their chemicals. Furthermore, they are responsible for their safe use. Selected substances are evaluated from public authorities and, if necessary, regulated. Substances of special concern have to go through an authorization procedure. As far as (micro)plastics are concerned, the European REACH Regulation already refers to plastic monomers and additives. The assessment of polymers within REACH is as follows: Because of their high molecular weight, polymer molecules are considered as being of low concern. They are exempted from registration and evaluation, unless the content of (unreacted) monomers exceeds certain limits or they contain certain additives triggering registration and evaluation [38].

\footnotetext{
${ }^{2}$ Presentation by Helen Clayton on the European Conference on plastics in freshwater systems, Federal Press Office, Berlin/Germany, June 21/22, 2016.

${ }^{3}$ Regulation concerning the Registration, Evaluation, Authorisation and Restriction of Chemicals.
} 


\section{$2.3 \quad$ National-Level Instruments}

Many national regulations support reducing the amount of (micro)plastic litter in freshwater systems. A selection of these is briefly presented in this section that neither claims to be complete nor to be an assessment. Most of the regulation-based activities aim at reduction actions preventing the environmental plastic pollution.

In the case of preventing littering, there are several regulatory instruments conceivable, for example, the prohibition (of any kind) of littering by prosecuting when disposing litter. Therefore, often a kind of penalty system is established. A non-exclusive list of countries, which have adopted littering acts, is provided in Table 1. As an example, the UK littering act is described below in more detail. In contrast to penalty systems, incentive schemes could be created to encourage a proper return of, e.g., packaging waste.

Table 1 Non-exclusive list of littering acts

\begin{tabular}{|c|c|}
\hline Country & Title \\
\hline \multicolumn{2}{|l|}{ Australia: } \\
\hline - Australian Capital Territory & Litter Regulations 1993 \\
\hline • New South Wales & Protection of the Environment Operations Act 1997 \\
\hline - Northern Territory & Litter Act 1972 \\
\hline - South Australia & Container Deposit Legislation $1977^{\mathrm{a}}$ \\
\hline • Tasmania & Litter Act 2007 \\
\hline - Queensland & Environmental Protection Act 1994 \\
\hline • Victoria & Litter Act 1987 \\
\hline - Western Australia & Litter Act 1979 \\
\hline \multicolumn{2}{|l|}{ United States of America (USA): } \\
\hline - Georgia ${ }^{\mathrm{b}}$ & Comprehensive Litter Prevention and Abatement Act 2006 \\
\hline - Idaho b & Comprehensive Litter Prevention and Abatement Act 2006 \\
\hline - Illinois ${ }^{\mathrm{b}}$ & Litter Control Act 1974 \\
\hline Ireland & Litter Pollution Act 1997 \\
\hline Jamaica & The Litter Act 1986 \\
\hline Malta & Litter Act 1968 \\
\hline New Zealand & Litter Act 1979 \\
\hline Canada, Saskatchewan & The Litter Control Act 2015 \\
\hline Scotland & $\begin{array}{l}\text { Environmental Protection Act } 1990 \\
\text { Code of Practice on Litter and Refuse (Scotland) } 2006 \\
\text { (COPLAR) }\end{array}$ \\
\hline South Africa & $\begin{array}{l}\text { White Paper on Integrated Pollution and Waste Management } \\
\text { for South Africa } 2000\end{array}$ \\
\hline Trinidad and Tobago & Litter Act 1973 \\
\hline United Kingdom (UK) & $\begin{array}{l}\text { Environmental Protection Act (EPA) } 1990 \\
\text { Clean Neighbourhoods and Environment Act (CNEA) } 2005\end{array}$ \\
\hline
\end{tabular}

Most of the acts have been amended since they took effect

${ }^{\mathrm{a}}$ Aim of reducing litter by encouraging recycling

b http://www.litterbutt.com/stop-litter/litter-laws-by-state.aspx provides a list of US litter laws 
In the UK, the Environmental Protection Act (EPA) of 1990 stated that it is an offense to throw down, drop, or otherwise deposit, and then to leave, litter. It enables bans and fines for littering any public places [39]. The Clean Neighbourhoods and Environment Act (CNEA) of 2005 amends the EPA, for example, that a principal litter authority is empowered to specify the amount of a fixed penalty to be applied for a littering offense [40].

In England, the Code of Practice on Litter and Refuse published by the Department for Environment, Food and Rural Affairs in 2006 "applies to all places that are open to the air, including private land and land covered by water. [...] There is no restriction on the type of litter for which this may be used, but it is intended primarily to help deal with food and drink packaging and other litter caused by eating "on-the-go" [41, p. 42f]. In this code, litter is defined as "materials, often associated with smoking, eating and drinking, that are improperly discarded and left by members of the public; or are spilt during business operations as well as waste management operations" [41, p. 11]. In addition, a law has been passed that requires large shops to charge 5 pence for all single-use plastic carrier bags starting on 5 October 2015. The charge was introduced trying to influence consumer behavior. In the first 6 months since introducing the charge, the plastic bag usage drops to approximately 85\% [42]. Wales (started charging in 2011), Northern Ireland (started charging in 2013), and Scotland (started charging in 2014) have also seen a significant drop in plastic bag usage.

In Scotland, The Litter (Fixed Penalties) (Scotland) Order 2013 [43], entering into force in 2014, prescribes fixed penalties for discharging any liability to conviction for the waste (including littering and flytipping) and littering offenses with reference to the EPA. The Scottish Litter Strategy [44], published in 2014 and based on research and extensive consultation, has three main goals to reduce and ultimately prevent litter and flytipping and to encourage personal responsibility and behavior change: "1. Information - improving communications, engagement and education around the issue. 2. Infrastructure - improving the facilities and services provided to reduce litter and promote recycling. 3. Enforcement - strengthening the deterrent effect of legislation and improving enforcement processes" (retrieved 13.11.2016 from http://www.zerowastescotland.org.uk/litter-flytipping/nationalstrategy).

As already mentioned in the section on regional regulation instruments, the Packaging and Packaging Waste Directive [21] calls on the member states to implement national deposit and return systems, in which disposed plastics are collected and recycled to allow their reuse as new packaging. This should contribute, among others, to a reduction of plastic inputs into freshwater environments. In Denmark, for instance, Dansk Retursystem A/S is such a privately owned nonprofit organization that is regulated by a statutory order (see https://www.danskretursystem.dk/). Another example for such a deposit and return system is the Irish company Repak (see https:/www.repak.ie/). Deposit and return systems incentivize to correctly dispose (plastic) litter and thus provide the advantage to keep plastics in the economic circle. 
Outside Europe, there are further deposit and return systems. In the USA, for instance, container deposit laws, known as bottle bills, are currently implemented in ten states. They require a minimum refundable deposit on beverage containers (usually 5 or 10 cents) in order to promote a high rate of recycling or reuse to reduce waste and prevent littering. By the bottle bills, the refund value of the container provides a monetary incentive to return the container for recycling (see http://www.bottlebill.org/).

Many countries have implemented waste management plans or schemes to prevent and reduce waste production, recover through reuse and recycling, and properly dispose the waste. This helps to prevent environmental pollution including the pollution of freshwater systems.

The Flanders Public Waste Agency (OVAM), developing and monitoring legislation and policies regarding waste management and soil remediation, initiated measures that included promoting source separation, subsidizing the construction of recycling and composting facilities, and discouraging waste. Hence, Flanders, the Flemish region of Belgium, reused, recycled, or composted almost three-fourths of the residential waste produced in this region and has also managed to stabilize waste generation [45]. Furthermore, within the framework of the Flemish Waste Regulation, general regulations that prohibit any kind of littering have been implemented.

The Luxembourgian Waste Management Plan [46] aims at preventing and reducing waste production and pollution from waste; recovering through reuse, recycling, and other environmentally appropriate methods; as well as disposing final waste in an environmentally and economically appropriate way. It set quantitative targets for recovery and recycling including packaging waste. It states that "[o]ther avoided emissions include the benefits of recycling of food and garden waste, paper, glass, metals, plastics, textiles and wood in the municipal solid waste" [47, p. 10].

Regulation instruments do not only address the end (i.e., waste) but also at the beginning of product life or product design. For instance, the UK's The Packaging (Essential Requirements) Regulations 2003 [48] urge the manufacturer to produce the packaging that its "volume and weight be limited to the minimum adequate amount to maintain the necessary level of safety, hygiene and acceptance for the packed product and for the consumer" and to design their products in such a way so as to permit its reuse and recovery and to minimize its environmental impact during the packaging waste disposal. Furthermore, the "Packaging shall be so manufactured that the presence of noxious and other hazardous substances and materials as constituents of the packaging material or of any of the packaging components is minimised with regard to their presence in emissions, ash or leachate when packaging or residues from management operations or packaging waste are incinerated or landfilled" [48, p. 7].

In the USA, for instance, the Microbead-Free Waters Act of 2015 [49], amending the Federal Food, Drug, and Cosmetic Act, prohibits "The manufacture or the introduction or delivery for introduction into interstate commerce of a rinseoff cosmetic that contains intentionally-added plastic microbeads." Here a plastic 
microbead is defined as "any solid plastic particle that is less than five millimeters in size and is intended to be used to exfoliate or cleanse the human body or any part thereof" (including toothpaste) [49, p. 1]. In this act, the term "microbead" is precisely defined. It refers to primary microplastics and thus provides a direct regulation instrument to tackle the problems related with it, e.g., the pollution of freshwater systems.

\section{Challenges of Current Regulation: Reasons and Requirements for Future Management}

As shown above, policy-makers are very aware of the problems of environmental plastic waste, and these issues are already considered in several regulatory documents. Nevertheless, most regulations do not clearly refer to microplastics. Therefore, this section aims to highlight the open questions and identify the challenges and the requirements for the future management of MP from the perspective of scientific authorities.

\subsection{Do We Need Regulation of Microplastics at All?}

Some critics debate the need for a regulation of MP and question whether it is only a "media-made" problem. Indeed, the general public's concern is driven by sensationalized media reports about enormous numbers of MP in the environment. However, there is little scientific data on adverse effects caused by relevant environmental concentrations of MP. Usually, effects were detected in laboratory studies that have tested concentrations far above measured environmental concentrations (see [50] for effects of MP to organisms). So far, only one study reports significant impacts of MP on fish larvae at concentrations found in coastal waters [51]. ${ }^{4}$

Nevertheless, MPs occur in almost all types of freshwater environments ranging from streams in densely populated areas to lakes in almost non-populated areas, e.g., in Mongolia ([52-55], [19, 56, 57]; see [58, 59] for further discussion). Additionally, MPs persist over centuries under common environmental conditions [60]. Thus, in the special case of such extremely persistent pollutants such as MPs, the motivation for any regulatory efforts should not be based solely on the demonstration of adverse effects at current environmental concentrations. If MP input into the environment continues at the current level, environmental concentrations will increase dramatically. Ubiquitous detection, persistency, and continuing release should motivate policy-makers and regulators to act immediately according to the precautionary principle to stop a further plastic accumulation.

\footnotetext{
${ }^{4}$ Note from the editors: The cited publication has been retracted because of scientific misconduct.
} 
Usually, regulation of pollutants in freshwater systems refers to dissolved chemicals, which are different to particulate matter with regard to their environmental fate (e.g., homogeneous versus inhomogeneous distribution). Therefore, we have to critically evaluate the transferability of regulatory options for dissolved chemicals to the issue of MPs. This represents a similar challenge as we know it from engineered nanomaterials. The development of regulation strategies for MP should consider more options than the simple adaptation of the existing regulation strategies for dissolved chemicals or suspended matter. Possibly, entirely new regulation strategies for MP in freshwater need to be developed. To start with, this requires a commonly accepted definition of "microplastics."

\subsection{A Precondition for Regulation: The Definition of Microplastics}

The term "microplastics" turned into a kind of buzzword in public communication and media, and it is understood as one specific type of pollutant. Hence, expectations rose to find solutions and regulations, which could consider all materials summarized by this single term. In contrast, the term "microplastics" refers to a large group of polymers with various chemical and physical properties, originating from different sources and entering the environment via different pathways (see $[3,59])$. Accordingly, these differences among MP particles apply to their environmental fate and persistence and, consequently, also to their bioavailability and potential impacts to organisms.

Verschoor [61] identified five commonly applied criteria to define MP: (1) synthetic materials with high polymer content, (2) solid particles, (3) $<5 \mathrm{~mm}$, (4) insoluble in water, and (5) not degradable. However, several points are still under discussion; e.g., some experts are still debating if tire abrasion should be considered as "microplastics" as the monitoring guidance documents for marine litter [62] categorize rubber originating from tires separately from plastics (discussed in more detail in [61]). This decision would significantly influence the measurement results of total environmental MP concentration.

The same applies to the definition of a lower limit for particle size, which is still under discussion. While it is commonly accepted to define all plastic items $<5 \mathrm{~mm}$ as MPs [e.g., 63], some authors categorize MPs into size-based subgroups. The MSFD Technical Subgroup on Marine Litter [62], for instance, differentiates between larger MPs (1-5 mm) and smaller MPs $(20 \mu \mathrm{m}$ to $1 \mathrm{~mm})$. Various studies set particular methodical limits as a lower size limit - e.g., mesh size of the sampling net or analytical detection limits. As "nano" refers to particles of 1-100 nm [64], the size limit for MPs should consequently start with a lower size limit of $100 \mathrm{~nm}$. Miklos et al. [65] base their size definition on this idea and suggest a size range on "microscale" from $100 \mathrm{~nm}$ to $100 \mu \mathrm{m}$. Depending on the thresholds defined for these criteria, completely different field concentrations would be 
obtained. Thus, these standards are fundamental for regulation purposes and should preferably be elaborated scientifically.

The debate about reasonable standards has to face some paradoxical points of discussion: On one hand, a lower limit for particle size would promote the standardization of sampling methods (see Sect. 3.5) and, thus, the elaboration of regulation standards. On the other hand, a lower size limit would exclude small particles from regulation. As MP particles are expected to continuously disintegrate into smaller fragments on sub-micrometer to nanometer scale, present MP particles are future nanoplastic particles, and thus, present regulatory measures on MP will also impact the future concentrations of nanoplastics. Additionally, sources and entry pathways are similar for particles with a wide size range. Therefore, it is questionable to what extent a further differentiation of micro- and nanoplastics is advantageous for the development of regulatory measures. The same plastic item might be documented and assessed as one MP particle in a current monitoring but as many nanoparticles in a future monitoring. From an ecotoxicological perspective, there is also no lower size limit: The smaller the particles are, the more species might potentially ingest those (see [50]). Furthermore, smaller particles can permeate through membranes and, hence, pose a higher risk for adverse effects in organisms. Against this background, it seems unreasonable to exclude small particles from regulation by defining a lower size limit. However, at the same time, general definitions are essential to bring regulatory measures forward. Measures are based on monitoring data, and monitoring again requires standardized and generally accepted methods. Clear guidelines for maximum and minimum particle sizes considered in sampling and analysis are required to generate reliable and legally valid monitoring data. Furthermore, regulation needs to assess the current environmental status with knowledge on the ecotoxicological impacts on organisms. As described, ecotoxicological effects are strongly related to particle size, which determine ingestion, membrane permeation, etc. Apart from size limits, regulators should think about an appropriate categorization of particle size classes. To conclude, final definitions of certain standards are fundamental for regulation purposes and should preferably be elaborated scientifically.

A first attempt to pave the way for future standards has been done by an ad hoc group (AHG) "Microplastics" under the International Organization for Standardization (ISO) Technical Committee (TC) 61 "Plastics." ISO decided to join all forces concerning environmental standards on the plastic issue under this technical committee in order to avoid duplicate work. The scope of this TC is standardization of nomenclature, methods of test, and specifications applicable to materials and products in the field of plastics. The AHG recommended to start a preliminary work item for an ISO technical report "Plastics: Recommendations for the Development of Standards for Investigations of Plastics in the Environment and Biota." It is generally agreed that a global environmental problem needs globally agreed standardization approaches covering the whole range from sampling to effect assessment in order to provide a basis for risk assessment and regulatory options. 


\subsection{Regulation by Groups?}

Besides their size, MP particles vary regarding further physicochemical properties. For regulators, the question follows if a single regulation strategy can address such a comprehensive group of diverse polymers or if it would be more reasonable to tailor regulations specifically to subgroups, especially since (micro)plastics do not solely consist of pure polymers but contain also a number of additives such as plasticizers, UV filters, antioxidants, etc. that alter product properties. Thus, the heterogeneity within the term "microplastics" arises from myriads of combinations of polymers and additives. To make things even more challenging, those additives can change the physicochemical properties and, consequently, also the environmental behavior of particles (for details, see [66]). Therefore, it seems reasonable to develop particular regulatory options focusing on special subgroups. This, in consequence, leads to the question about the main criteria required for a categorization into single groups. Of course, any categorization is depending on the regulatory context and the life stage of a product, as described below. While it can be useful to categorize into very specific subgroups for specific regulatory purposes, in other cases, it might be more efficient to evaluate the whole group of MPs.

As a first approach for MP assessment in freshwater environments, Miklos et al. [65] suggest a modular system starting with the quantification of selected indicator polymers. As soon as the concentration of these polymers exceeds a certain level, more specific analyses should be conducted. These subsequent analyses can take various criteria (such as polymer type, size, shape, additives, etc.) into consideration to further categorize the particles and support the selection of adequate mitigation measures. Here, approaches from chemical regulation might serve as examples.

Chemicals can be categorized based on molecular similarities (e.g., PAHs, PCBs, etc.), by the field of application (e.g., pesticides), or according to their mode of action (e.g., endocrine disruptors). So far, mainly sum parameters for molecularly similar chemicals are implemented to freshwater directives (e.g., dioxin + dlPCB, cyclodiene pesticides, EU WFD). Similarly, MPs could be grouped based on their physicochemical properties (e.g., polymer type, density), by their application fields (e.g., cosmetics, carrier bags, electrical devices), or by (eco)toxicological impacts. The latter might be difficult as little is known about the biological effects of MP, and it will take time to generate comprehensive data (see [50]). In contrast to chemical pollutants, MP can cause both chemical and additionally mechanical effects on organisms. Chemical effects could be caused by the polymers themselves, by their additives, or by a combination of both. Similarly, an occurrence of mechanical effects could depend on particle size, particle shape, or a combination of both. It follows that (eco)toxicologists face the challenge to test the effects of myriads of combinations. Hence, there are efforts to prioritize and start with the presumed most harmful combinations. Ideally, these results will be transferable to a group of similar combinations. 
However, ecotoxicity-derived groups are not necessarily suitable for regulation purposes: As each MP particle has unique physicochemical properties (individual polymers, additives, size, shape, etc.), it will induce a unique set of modes of action. Accordingly, one would - in theory - need to perform a multiple stressor assessment of each single particle, which is in itself a complex mixture. From a practical perspective, the integration from multiple stressors in risk assessment is challenging - traditionally each stressor is considered individually. For instance, existing regulations refer to the total concentration of suspended particulate matter (SPM) or for single pollutants adsorbed to SPM. Currently, chemical and particulate parameters are not integrated - as would be required for MP regulation.

Hence, an alternative approach to categorize MP for regulation might by the field of application or by the source for environmental entry. Plastics are used in a wide range of applications including packaging, construction materials, cosmetics, electrical and even medical devices, etc. Obviously, distinct regulatory measures are required to manage the proper recycling of electronic devices compared to throwaway packaging materials or to reduce MP in cosmetics - even though the same polymers might be used in these completely different products. In consequence of their broad use, (micro)plastics enter ecosystems via various pathways. Hence, regulatory measures must not necessarily refer to groups based on MP properties but can also act on groups of sources or entry pathways such as wastewater, incorrect disposal, or agricultural runoff.

As we have seen above, we have different options of grouping MPs. The microbead ban, to name just one example from practice, clearly categorizes MPs by the field of application (cosmetics/personal care products). Which characteristics one select for categorization depends on the regulatory context.

Environmental policy has developed a long list of general and specific management options applicable to a variety of environmental issues (including waste management and water resource management). Some of these might be adopted for the regulation of MPs.

\subsection{General Regulation Options by Environmental Policy: Applicable for MP?}

Environmental policy aiming at protecting ecosystems and improving the environmental status can be implemented by various regulatory instruments and measures. An intervention can take place on different statutory levels - ranging from voluntary commitments to legally binding bans of certain materials. Furthermore, the interventions can differ regarding the implementation level - including direct regulation of production and application of materials, improvement of waste and water management, and long-term measures aiming at social awareness and changing of behavior. Exhaustive compilations regarding environmental policy instruments are given, e.g., by the OECD $[67,68]$. Some of those generally applicable 
instruments might be transferable to the regulation of MP in freshwater environments. In Fig. 2, some examples are categorized according to the three main types of environmental policy into "regulative," "economic," and "persuasive" instruments. Each category comprises instruments from different statutory and implementation levels. Within each main category, we rated the instruments from "hard" to "soft," depending on how strict measures would affect the application of certain materials. On the horizontal scale, the figure emphasizes the gradient from a "direct" to an "indirect" influence of the regulatory action. The figure does not provide a full compilation of policy tools but rather gives an overview of the range of possible instruments on different implementation levels that could be of interest for the regulation of MP.

In the case of MPs, the choice of regulatory instruments depends on several aspects. It is conceivable that "command and control" (CaC, Fig. 2) instruments such as bans or limitations could either apply to certain polymers, to additives, or to their combination. Similarly, they could be limited to a certain field of application. Measures targeted on certain fields of application could either relate to specific

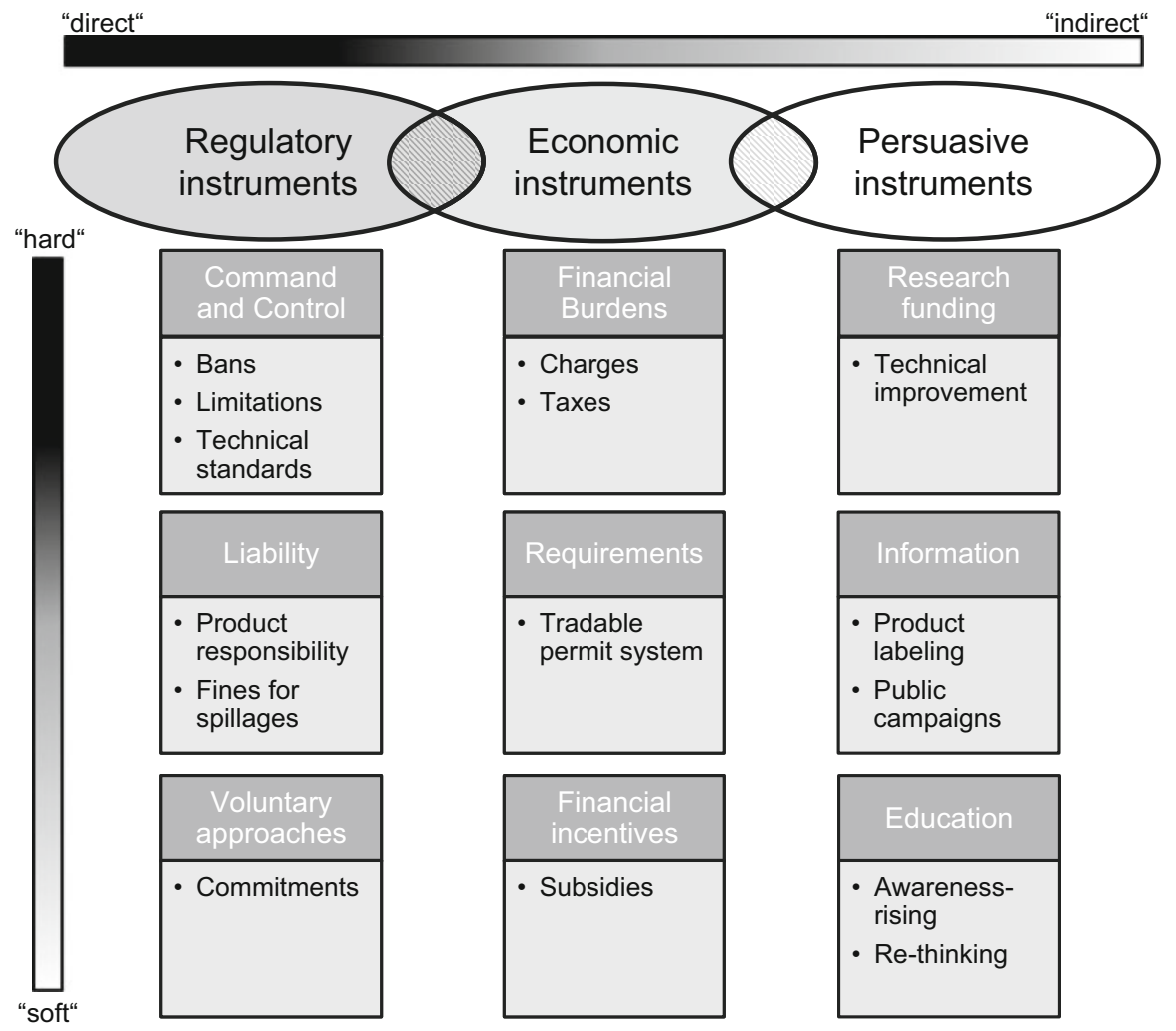

Fig. 2 Instruments of environmental policy, which might be applicable to a regulation of (micro) plastics in freshwater environments (based on [68]) 
materials or to MPs in general. To give an example, food packaging should not contain any polymers or polymer-additive combinations that could pose any risk to human health by leaching into food products. The same polymer-additive combination might be less harmful in products without direct contact to food and environment. Hence, limitations can be restricted to certain fields of application provided that proper waste management ensures competent disposal or recycling.

In contrast to the above given example, the Microbead-Free Waters Act 2015 [49] applies not solely to selected materials but bans MPs in general from an application in personal care products (for details, see Sect. 2.3). In rinse-off cosmetic products, where MPs could easily be replaced with natural materials that have similar functions, an entry of MPs into the environment is consciously accepted. "Hard" measures, such as bans and limitations, can potentially be applied to plastic applications that are either not needed for the function of a product or do not benefit the user or can easily be replaced by other materials. In contrast, "softer" instruments need to be applied in areas in which the use of plastics is indisputable (e.g., medical devices).

Regulatory instruments to reduce the emission of MP into the aquatic environment need not necessarily affect production or application but can also be related to an improvement of the management of wastewater and solid waste. Requirements on improved technical standards can be implemented on different levels in a product life cycle. Starting with product design, the range of possibilities includes degradable polymers, polymers with high recycling quotas, or a product design promoting a long and circular product life to reduce waste (see [32]). At the end of product life, enhanced recycling systems can prolong the service time of raw materials to avoid disposal. Any emission of unavoidable waste to the environment needs to be reduced by further regulations. This might be achieved by technical innovations ("CaC") or by a stricter product responsibility from the producer side ("liability").

Economic measures to achieve environmental goals are well known from other fields. They range from imposing financial burden (e.g., taxation) to flexible systems with tradable permits (e.g., $\mathrm{CO}_{2}$ emission trading) and to financial incentives for increasing recycling rates, to name just a few. With regard to the latter, recycling rates for plastic bottles and further containers for water, soft drinks, milk, etc. increased considerably since the introduction of a container deposit system in several European countries. Deposit systems would be transferable to further plastic-based products (e.g., packaging, carrier bags, etc.)

One of the most sustainable measures would be a social change, with regard to a transformation from a society with linear resource use toward a recycling society, valuing plastics as a precious resource. To achieve such long-term objectives, policy can apply so-called persuasive instruments such as public information, environmental education, and funding of research and development. Compared to the instruments on the left side of Fig. 2, these measures are softer, and effects are less direct. Nevertheless, they might lead to long-lasting input reduction of plastics, MPs, and even further pollutants into the environment. 
In case of the heterogeneous group of (micro)plastics, it is important to develop a set of different measures to tackle the problem from different sides. This set might include measures well known from similar environmental issues, ideally complemented with new and specific strategies. The choice of suitable measures depends on the characteristics of the plastics under regulation, on their intended application, and on their current stage of product life cycle. With regard to the latter, various regulatory measures can be applied to one plastic product, as the regulatory responsibilities change during product life. The main stages of product life are schematized in Fig. 3 to emphasize that the management of plastics involves different regulatory authorities as well as various addressees.

As we have seen above, various $\mathrm{CaC}$ measures can affect plastic products mainly at the beginning (production, product design) and end (recycling, disposal) of product life. During the actually intended use and function of the product, regulatory measures address consumers and are often realized by financial or persuasive measures. Regulations related to freshwater do usually not concern the intended product life. Plastics usually enter into freshwater systems in consequence of incorrect disposal or insufficient treatment after their intended product life has

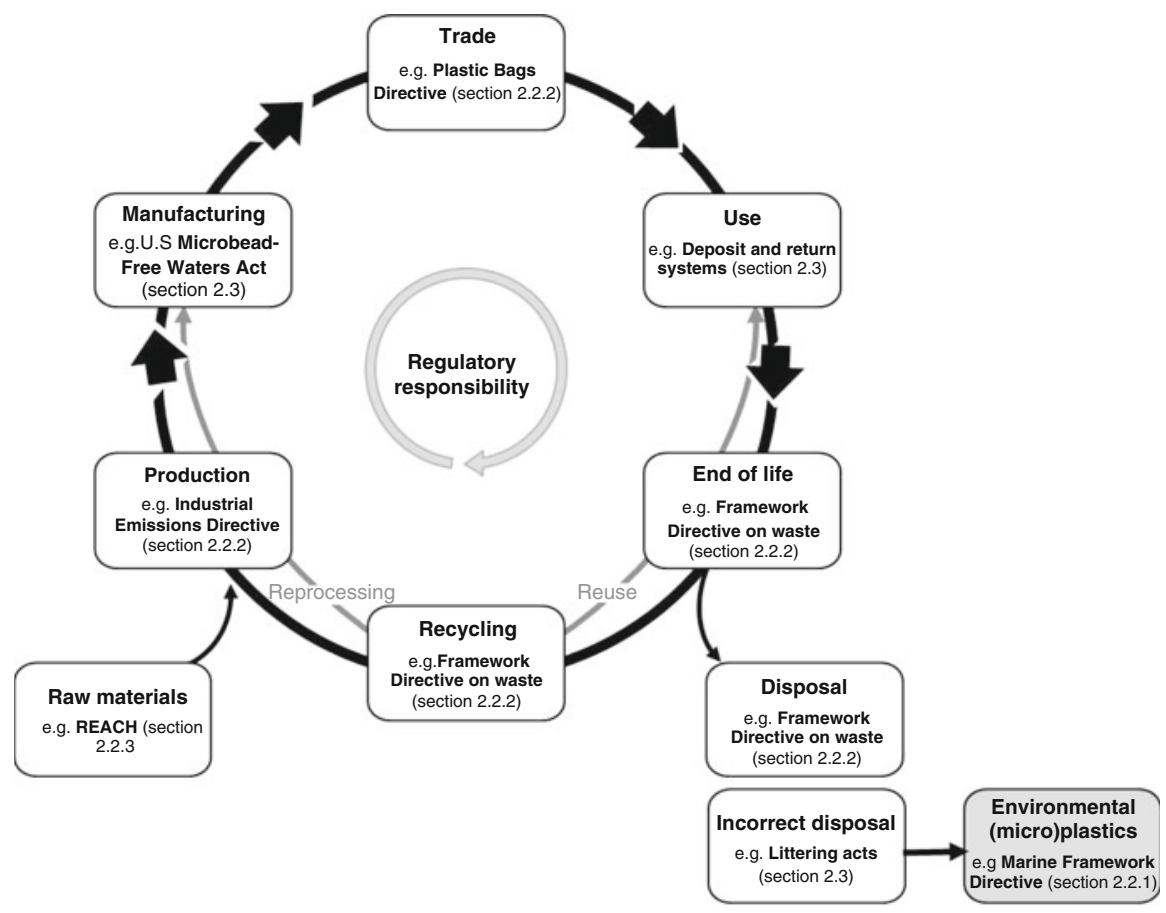

Fig. 3 Main stations in the life cycle of plastic products. Regulatory responsibilities and addressees of regulatory measures change during product life. Examples for regulatory instruments are given for each stage of product life. Environmental plastics mostly occur from incorrect disposal of plastic products after their intended product life has expired 
expired. Hence, regulatory measures in early product life stages should minimize plastic waste that could be released into the environment.

However, currently (micro)plastics enter freshwater systems, and monitoring programs need to evaluate the environmental status quo to develop adequate measures. For instance, the type of (micro)plastic and its entry path into the environment should be considered: Depending on their application, plastics enter the environment as macroplastics, secondary microplastics, or primary microplastics (for definition, see [3]). The regulation of primary MP seems to be closer related to the regulation of chemical pollutants: production, application, and entry into the environment are traceable to a certain extent. In freshwater monitoring, source and polluter can potentially be identified, similar to chemical polluters. It has to be noted that the application of some primary MPs even accepts its intended entry into the water cycle, for instance, in the application of MPs in personal care products or as blasting abrasives for cleansing of surfaces (e.g., wheel rims of cars; [69, 70]).

Secondary MPs, in contrast, are not easily traceable due to their various sources and entry pathways. As to their potentially long fate in the environment, the polluter can rarely be identified, and, as a result, it is hardly possible to apply the polluterpays principle. Secondary MPs usually originate from larger plastic products, which are originally intended to be correctly recycled or disposed. Incorrect disposal (by purpose or because of lacking waste management) leads to fragmentation and distribution of smaller particles in environmental systems. Thus, regulatory measures should intervene before an unintended fragmentation of plastics into MPs can occur. Reasonable strategies should have positive effects on a global level and should be able to prevent the (micro)plastic problems even in regions that lack proper waste management (see [32]).

\subsection{Standardization of Sampling and Analysis}

The implementation of any regulation measure implies the existence of reliable monitoring data on the status quo and temporal trends in the environment.

In environmental monitoring for regulatory purposes, standardized and harmonized procedures are a prerequisite for reliable, generally accepted, and justiciable data acquisition. On several conferences on plastics in the environment, stakeholders agreed that there is a considerable - not to say a complete - lack of standards for sampling, sample preparation, chemical analysis, and the analysis of biological effects in the field of plastic contamination. A fundamental challenge lies in the fact that the issue of plastic materials in different environmental compartments differs from classical environmental monitoring and assessment issues. Classical monitoring of chemical contamination, e.g., according to the EU WFD, mainly addresses dissolved or particle-bound chemicals in the waterbody or in biota. The plastic contamination issue concerns undissolved material with an extremely inhomogeneous distribution pattern. Up to now, knowledge about 
representative sampling in wastewater streams and rivers under different hydrological conditions is missing. The picture is similar for sample processing, chemical analysis, sample throughput, and biological effect methods. Crucial criteria like water depth for sampling or mesh size of sampling nets need to be standardized. As mentioned above, such criteria can significantly influence the monitoring results. A marine study conducted in Swedish coastal waters revealed $10^{5}$-fold higher concentrations of MP using $80 \mu \mathrm{m}$ nets compared to $450 \mu \mathrm{m}$ nets [71].

Besides a lack of sampling guidelines, no standardized methods for chemical analysis of MP particles in environmental samples exist, so far. The problem starts with sample processing which is a precondition for a precise analysis of plastic particles. Several methods are under development (as summarized in [58]). Some of them are time and work intensive; others are suspected to corrode the plastic items. A generally accepted method for extensive application has still to be developed. However, the required sample cleanup depends on the analysis methods applied. Currently, two main directions of analytical methods are applied to identify MP: spectroscopy and thermogravimetry (see [58]). For both, several techniques exist for the identification of polymer types. However, the choice of a certain technique is determining the outcome less than the choice of the main direction of methods: Spectroscopic methods (e.g., IR microscopy or Raman) can lead to an exact definition of single particles regarding size, shape, color, and main polymer type but are not appropriate for exact mass balancing. In contrast, thermogravimetric methods (e.g., TED-GC-MS or pyrolysis GC-MS) can quantify the exact mass of certain polymers in environmental samples - but thermal degradation of particles does not allow any further characterization of particles. Both directions are appropriate to answer specific questions. (Waste)water management will be more interested in mass balances, while ecology and water conservation will rather ask for an exact description of particle size distribution in order to assess the risk to organisms.

\subsection{Mass Balance Versus Particle Characterization as Criterion for Regulation}

The choice of mass versus particle concentration depends on the aims of regulation. To give some examples:

The EU MSFD [4] aims to regulate the contribution of plastic waste from single member states to the marine environment via rivers. Here, it seems obvious for the regulation to require information on mass balances instead of particle numbers because (1) the regulation aims to impose financial penalties depending on the contribution of each state to the overall plastic load and (2) plastic particles may disintegrate and break into more pieces on their way through different countries. If regulation should refer to the impact on freshwater ecosystems, it will ask about ecotoxicological effects of MP, for instance. Hence, such regulation requires 
Table 2 Overview of the advantages and disadvantages of mass balance versus particle characterization as criteria for regulation

\begin{tabular}{|c|c|c|c|}
\hline \multicolumn{2}{|l|}{ Particle concentration } & \multicolumn{2}{|l|}{ Mass concentration } \\
\hline Pro & Contra & Pro & Contra \\
\hline \multirow{3}{*}{$\begin{array}{l}- \text { Information about } \\
\text { size, shape, color } \\
\rightarrow \text { Ecotoxicological } \\
\text { relevance } \\
\rightarrow \text { Distinguish primary } \\
\text { and secondary MP } \\
>\begin{array}{l}\text { Enables source } \\
\text { tracking }\end{array}\end{array}$} & $\begin{array}{l}\text { - No exact mass } \\
\text { quantification }\end{array}$ & $\begin{array}{l}\text { - Exact mass } \\
\text { quantification }\end{array}$ & \multirow{2}{*}{$\begin{array}{l}\text { No further charac- } \\
\text { terization of } \\
\text { particles }\end{array}$} \\
\hline & \multirow[b]{2}{*}{$\begin{array}{l}\text { - Snapshot } \\
\rightarrow \text { Due to continu- } \\
\text { ous fragmenta- } \\
\text { tion under } \\
\text { environmental } \\
\text { conditions }\end{array}$} & \multirow{2}{*}{$\begin{array}{l}\text { - Fits to conven- } \\
\text { tional regulation } \\
\text { options }\end{array}$} & \\
\hline & & & $\begin{aligned} \rightarrow & \text { Less } \\
& \text { information }\end{aligned}$ \\
\hline \multicolumn{2}{|c|}{ Appropriate for ecotoxicological questions } & \multicolumn{2}{|c|}{ Appropriate for water management } \\
\hline
\end{tabular}

information on particle number, shape, and size distribution to assess a potential ingestion by organisms and resulting adverse effects. Table 2 gives an overview on the advantages and disadvantages on both sides.

Apart from any discussion about numbers versus mass balances, further discordances reduce the comparability of monitoring data. Currently, masses or numbers are reported in various units as per $\mathrm{m}^{2}$ water surface, per $\mathrm{m}^{3}$ water volume, per $\mathrm{m}^{2}$ sediment surface, per liter sediment, or per kg sediment, to name just a few. For regulation purpose, comparable units need to be defined and generally applied.

\subsection{Adaptation of Ecotoxicological Test Systems}

The previous paragraphs discuss the challenges related to the exposure assessment of MPs. Furthermore, comprehensive hazard assessment is required to evaluate the environmental risk of MPs and subsequently formulate reasonable regulation strategies. As described above, particulate pollutants behave differently than dissolved chemicals, and thus, an adaption of test systems of toxicity tests for dissolved chemicals could be required. With regard to this, there is some experience from studies on engineered nanomaterials (see [72]). Researchers can learn from those experiences; however, they need to consider that physicochemical properties of MP might lead to again different behavior in test systems. High-density polymers will sink to sediments. Hence, sediment-living species are required - comparable to the testing of highly lipophilic, sediment-bound chemicals. Vice versa, low-density polymers will float and will only be available for surface-feeding organisms. Those will be at higher risk in environmental systems as they might feed selectively on floating materials and accumulate them from the water phase. Chemical testing is usually not focused on this feeding type.

Furthermore, MP particles can impact organisms in various manners - chemically and mechanically (see [50]). One particle can be seen as a multiple stressor itself. Hence, ecotoxicologists have to face different challenges and to adapt common test systems and endpoints. Potentially, the chosen endpoints of mono-substance test designs simply overlook the effects of MP. Fundamental research would be required 
to formulate the right questions and to adapt or develop suitable test designs with adequate endpoints. This also applies to biomarkers used in field studies.

Above all, scientists should consider that organisms are adapted to natural particles of different materials (sand, clay, or similar), but with similar properties as MP, in their natural habitats. It is crucial to perform tests on MP particles in comparison with such natural particles. This applies especially to tests regarding the "Trojan horse effect" - the transport of hydrophobic substances via MP into organisms (see [50]). Studies need to address whether there are differences in the sorption of chemicals to MP versus natural particles and, consequently, in the impact to organisms. In fact, there are regulations for priority substances bound to suspended matter - and MP particles are included in the suspended matter. Unfortunately, most ecotoxicological studies lack a direct comparison of suspended matter spiked with chemicals toward spiked MP particles. Knowledge about those aspects could help to prioritize regulatory questions.

\subsection{The Information Base for Regulation: Too Scarce? Too Much? Inapplicable?}

Even though scientists continuously provide new findings about MPs, it still provides a huge challenge for numerous scientific fields. The group of MPs comprises particles with countless physicochemical properties determining their environmental fate and risk to organisms. It seems to be a playground for researchers to investigate open questions ranging from degradation process, uptake by organisms, and interaction with chemicals to special surface properties of aged plastics. Knowledge about those aspects is fundamental but in sum too complex to be considered for regulation.

We have to formulate what information is needed for regulation and what kind exceeds the scope of generalized regulation instruments. While the current lack of knowledge is obvious, this should not serve as a general excuse for delaying an implementation of regulation instruments for those persistent materials. To refer to the initial statements of this chapter, we have to ask ourselves which kind of knowledge is required to justify the need for regulation of highly persistent MP?

While we can clearly state that regulatory strategies for a reduction of environmental (micro)plastics are urgently needed, many questions about the implementation of monitoring and regulatory strategies are still open:

- How to define microplastics?

- Can we adopt existing regulative options or do we need to develop new strategies?

- Which criteria can categorize MPs for regulatory purpose?

- Which particles have to be regulated with priority?

- Which monitoring methods can adequately answer regulatory questions? 
- How should standardization of monitoring methods look like?

- How can ecotoxicological test designs be adopted for an assessment of combined chemical and mechanical effects?

- What are the relevant sources and pathways into the environment?

- Which measures can reduce MP entry into the environment?

However, the list of questions could be continued far beyond the one above especially with regard to different perspectives as human toxicology, drinking water supply, etc. exceeding the scope of this freshwater-related chapter. Nevertheless, it emphasizes the need of interdisciplinary cooperation to address the issue of freshwater (micro)plastics.

\section{Conclusions}

This chapter provided a rough overview of the existing regulation instruments developed at international, regional, and national levels to address freshwater (micro)plastics. While several regulations address plastics, concrete regulations on microplastics - especially with regard to freshwater systems - are rare. Hence, we discussed possible reasons for that and formulated a list of questions to be answered with priority.

Despite many open questions, we want to conclude that:

- In our point of view, regulation of freshwater (micro)plastics is urgently required.

- An important step toward the management of environmental (micro)plastics has been accomplished by awareness raising in society and policy.

- International and intergovernmental bodies already discuss measures to reduce environmental plastics (e.g., UN, G7, World Bank, World Economic Forum)

- So far, policy-makers integrated the (micro)plastic issue into a few regulatory directives on international and national level.

- These regulations concern diverse fields of policy (e.g., chemical regulation, waste management, water resource management).

- Environmental policy provides a long list of instruments, which might be adopted to develop further management options for the issue of MP.

Nevertheless, further research should be promoted to fill current knowledge gaps. The compilation of challenges for regulation and management as presented in Sect. 3 highlights the most important needs from the perspective of freshwater monitoring. Thus, the key issues to be tackled in a systematic approach are:

- Microplastics are a heterogeneous group of pollutants.

- Hence, a definition of regulatory (sub)groups is as important as the definition of MPs itself in order to define management options more precisely.

- As MPs are mainly derived from larger plastic items, its management needs to be closely linked to the regulation of plastic production, consumption, and litter. 
- MPs in the freshwater environment are already outside their intended product cycle. Hence, it is difficult to address responsible stakeholders (producer, consumer, waste manager, etc.).

- Thus, it is even more important to clarify entry pathways into aquatic environment, to define standardized methods for exposure and hazard assessment, and to work in an integrated approach.

An adequate regulation of environmental (micro)plastics is a huge challenge for research and policy. As plastics influence all parts of society, single fields of science or policy cannot tackle this issue individually. During the lifetime of a single plastic product - from design and production to trade and consumption to the correct recycling or disposal at the end of its functional product life - regulatory responsibilities change. This provides various possibilities for regulators to intervene before plastics enter the environment. However, it requires an interdisciplinary coordination of measures on different statutory, political, economic, and social levels.

Only the interplay between all stakeholders from all countries results in success. (Micro)plastic particles do not respect political frontiers and, thus, accumulate in interregional waterbodies. For this reason, the need to treat this emerging environmental issue in an international context is increasing. Although - or precisely because - we currently know little about the consequences of MPs in aquatic systems, we should develop and implement measures to reduce further emissions. This is especially true regarding the high persistence and accumulation of these materials in the environment and in accordance with the precautionary principle.

\section{References}

1. Kramm J, Völker C (2017) Understanding the risks of microplastics. A social-ecological risk perspective. In: Wagner M, Lambert S (eds) Freshwater microplastics: emerging environmental contaminants? Springer, Heidelberg. doi:10.1007/978-3-319-61615-5_11 (in this volume)

2. Breuninger E, Bänsch-Baltruschat B, Brennholt N, Hatzky S, Reifferscheid G, Koschorreck J (2016) Plastics in European freshwater environments. Issue paper (final version). In: BänschBaltruschat B, Brennholt N, Kochleus C, Reifferscheid G, Koschorreck J Conference on plastics in freshwater environments. pp 16-71. UBA Dokumentationen 05/2017. ISSN 21996571

3. Lambert S, Wagner M (2017) Microplastics are contaminants of emerging concern in freshwater environments: an overview. In: Wagner M, Lambert S (eds) Freshwater microplastics: emerging environmental contaminants? Springer, Heidelberg. doi:10.1007/978-3-319-616155_1 (in this volume)

4. EU (2008) Directive 2008/56/EC of the European Parliament and of the Council of 17 June 2008 establishing a framework for community action in the field of marine environmental policy. Marine Strategy Framework Directive (MSFD). http://eur-lex.europa.eu. Retrieved 4 May 2009

5. Chen C-L (2015) Regulation and management of marine litter. In: Bergmann M, Gutow L, Klages M (eds) Marine anthropogenic litter. Springer, Berlin, pp 185-200 
6. Gordon M (2006) Eliminating Land-based discharges of Marine Debris. In: California State Water Resources Control Board. California: A Plan of Action from The Plastic Debris Project. Sacramento

7. EU (2000) Directive 2000/60/EC of the European Parliament and of the Council of 23 October 2000 establishing a framework for Community action in the field of water policy. Water Framework Directive (WFD). http://eur-lex.europa.eu. Retrieved 4 May 2009

8. EU (2007) The Lisbon Treaty. http://www.lisbon-treaty.org/wcm/. Retrieved 09 Nov 2016

9. UN (2015) Transforming our world: the 2030 Agenda for Sustainable Development. Resolution No. A /RES/70/1 adopted by the General Assembly of the United Nations on 25 Sep 2015

10. G7 (2015) Leaders' Declaration G7 Summit, 7-8 June 2015. Schloss Elmau, Germany, pp $17-18$

11. G7 (2015) Annex to the Leaders' Declaration G7 Summit, 7-8 June 2015. Schloss Elmau, Germany, pp 9-11

12. WEF (2016) The New Plastics Economy: Rethinking the future of plastics. Industry Agenda by the World Economic Forum. p 36. https://www.weforum.org/reports/the-new-plasticseconomy-rethinking-the-future-of-plastics/

13. Hoornweg D, Bhada-Tata P (2012) What a Waste - A Global Review of Solid Waste Management. Urban Development Series Knowledge Papers No. 15. p 116. http:// siteresources.worldbank.org/INTURBANDEVELOPMENT/Resources/3363871334852610766/What_a_Waste2012_Final.pdf

14. PMEH (2016) Supporting Pollution Action for Health. Pollution Management \& Environmental Health Program Annual Report 2016. p 56. http://documents.worldbank.org/curated/en/ 905491479734253523/pdf/110353-AR-PMEHAnnualRprtFINALWEBHI-PUBLIC.

pdfREACH. Regulation (EC) No 1907/2006 of the European Parliament and of the Council of 18 December 2006 concerning the Registration, Evaluation, Authorisation and Restriction of Chemicals

15. Gorycka M (2009) Environmental risks of microplastics. Faculteit der Aard- en Levenswetenschappen, Vrije Universiteit Amsterdam, Amsterdam, p 171

16. Wesch C, Stöfen A, Klein R, Paulus M (2014) Microplastics in freshwater environments: a need for scientific research and legal regulation in the context of the European water framework directive. Zeitschrift für Europäisches Umwelt- und Planungsrecht 12:258-274

17. EU (1991) Council Directive of 21 May 1991 concerning urban waste water treatment (91/271/ EEC) (Urban Waste Water Treatment Directive). http://eur-ex.europa.eu. Retrieved 4 May 2009

18. U.S. (2002) Federal Water Pollution Control Act [As Amended Through P.L. 107-303, November 27, 2002]. Clean Water Act (CWA). https://www.epw.senate.gov/water.pdf. Retrieved 12 Nov 2016

19. Moore CJ, Lattin GL, Zellers AF (2011) Quantity and type of plastic debris flowing from two urban rivers to coastal waters and beaches of Southern California. J Integr Coast Zone Manag $11: 65-73$

20. Moore CJ (2008) Synthetic polymers in the marine environment: a rapidly increasing, longterm threat. Environ Res 108:131-139

21. EU (1994) European Parliament and Council Directive 94/62/EC of 20 December 1994 on packaging and packaging waste. http://eurlex.europa.eu. Retrieved 12 Nov 2016

22. EU (2004) Directive 2004/12/EC of the European Parliament and of the Council of 11 February 2004 amending Directive 94/62/EC on packaging and packaging waste. http://eurlex.europa. eu. Retrieved 12 May 2009

23. EU (2015) Directive (EU) 2015/720 of the European Parliament and of the Council of 29 April 2015 amending Directive 94/62/EC as regards reducing the consumption of lightweight plastic carrier bags. http://eurlex.europa.eu. Retrieved 11 Nov 2016

24. EU (2008) Directive 2008/98/EC of the European Parliament and of the Council of 19 November 2008 on waste and repealing certain Directives. http://eur-lex.europa.eu. Retrieved 12 Nov 2016 
25. EU (1994) European Parliament and Council Directive 94/62/EC of 20 December 1994 on packaging and packaging waste. http://eur-lex.europa.eu. Retrieved 12 Nov 2016

26. EU (2000) Directive 2000/53/EC of the European Parliament and of the Council of 18 September 2000 on end-of life vehicles. http://eur-lex.europa.eu. Retrieved 12 Nov 2016

27. EU (2002) Directive 2002/96/EC of the European Parliament and of the Council of 27 January 2003 on waste electrical and electronic equipment (WEEE). http://eur-lex.europa.eu. Retrieved 12 Nov 2016

28. EU (2006) Directive 2006/66/EC of the European Parliament and of the Council of 6 September 2006 on batteries and accumulators and waste batteries and accumulators and repealing Directive 91/157/EEC. http://eur-lex.europa.eu. Retrieved 12 Nov 2016

29. EU (2004) Directive 2004/35/CE of the European Parliament and of the Council of 21 April 2004 on environmental liability with regard to the prevention and remedying of environmental damage. http://eur-lex.europa.eu. Retrieved 08 Nov 2016

30. EU (1999) Council Directive 1999/31/EC of 26 April 1999 on the landfill of waste. http://eurlex.europa.eu. Retrieved 12 Nov 2016

31. European Commission (2014) COM/2014/0397. Proposal for a Directive of the European Parliament and of the Council amending Directives 2008/98/EC on waste, 94/62/EC on packaging and packaging waste, 1999/31/EC on the landfill of waste, 2000/53/EC on endof-life vehicles, 2006/66/EC on batteries and accumulators and waste batteries and accumulators, and 2012/19/EU on waste electrical and electronic equipment. http://eur-lex.europa.eu. Retrieved 12 Nov 2016

32. Eriksen M, Thiel M, Prindiville M, Kiessling T (2017) Microplastic: what are the solutions? In: Wagner M, Lambert S (eds) Freshwater microplastics: emerging environmental contaminants? Springer, Heidelberg. doi:10.1007/978-3-319-61615-5_13 (in this volume)

33. European Commission (2015) Closing the loop: Commission adopts ambitious new Circular Economy Package to boost competitiveness, create jobs and generate sustainable growth. Press release, Brussels, 2 December 2015, IP/15/6203. http://europa.eu/rapid/press-release_IP-156203 en.htm. Retrieved 13 Nov 2016

34. Plastics circular economy strategy not due until end of 2017. ENDS Europe DAILY. ISSN 1463-1776, www.endseurope.com/article/47616/

35. EU (2010) Directive 2010/75/EU of the European Parliament and of the Council of 24 November 2010 on industrial emissions (integrated pollution prevention and control). http://eur-lex.europa.eu. Retrieved 13 Nov 2016

36. European Commission (2013) Green Paper on a European Strategy on Plastic Waste in the Environment. /* COM/2013/0123 final */. Document 52013DC0123. http://eur-lex.europa.eu/ legal-content/EN/TXT/?uri=CELEX:52013DC0123. Retrieved 10 Nov 2016

37. EU (2006) Regulation (EC) No 1907/2006 of the European Parliament and of the Council of 18 December 2006 concerning the Registration, Evaluation, Authorisation and Restriction of Chemicals (REACH), establishing a European Chemicals Agency, amending Directive 1999/ 45/EC and repealing Council Regulation (EEC) No 793/93 and Commission Regulation (EC) No 1488/94 as well as Council Directive 76/769/EEC and Commission Directives 91/155/EEC, 93/67/EEC, 93/105/EC and 2000/21/EC. http://eur-lex.europa.eu. Retrieved 11 Nov 2016

38. ECHA (2012) Guidance for monomers and polymers. ECHA-12-G-02-EN. European Chemicals Agency. http://echa.europa.eu/. Retrieved 11 Nov 2016

39. UK (1990) Environmental Protection Act 1990. http://www.legislation.gov.uk. Retrieved 13 Nov 2016

40. UK (2005) Clean Neighbourhoods and Environment Act 2005. http://www.legislation.gov.uk. Retrieved 13 Nov 2016

41. DEFRA (2006) Code of Practice on Litter and Refuse 2006. https://www.gov.uk/government/ uploads/system/uploads/attachment_data/file/221087/pb11577b-cop-litter.pdf. Retrieved 13 Nov 2016 
42. https://www.gov.uk/government/publications/carrier-bag-charge-summary-of-data-inengland-for-2015-to-2016/single-use-plastic-carrier-bags-charge-data-in-england-for-2015to-2016. Data Retrieved 13 Nov 2016

43. UK (2013) The Litter (Fixed Penalties) (Scotland) Order 2013. http://www.legislation.gov.uk. Retrieved 13 Nov 2016

44. Scottish Government (2014) Zero Waste - Towards A Litter-Free Scotland: A Strategic Approach To Higher Quality Local Environments. http://www.gov.scot/Resource/0045/ 00452542.pdf. Retrieved 13 Nov 2016

45. Allen C (2012) Flanders, Belgium: Europe's Best Recycling and Prevention Program. Global Alliance for Incinerator Alternatives (GAIA)

46. PGGD (2010) Plan général de gestion des déchets. Published by the Government of Luxembourg. Ministry of Sustainable Development and Infrastructures. Environment Administration. Luxembourg, $404 \mathrm{pp}$

47. European Environment Agency (2013) Municipal waste management in Luxembourg. ETC/SCP working paper prepared by Emmanuel C. Gentil, Copenhagen Resource Institute

48. UK (2003) The Packaging (Essential Requirements) Regulations 2003. http://www.legislation. gov.uk. Retrieved 13 Nov 2016

49. U.S. (2015) Microbead-Free Waters Act of 2015. https://www.congress.gov. Retrieved 13 Nov 2016

50. Scherer C, Weber A, Lambert S, Wagner M (2017) Interactions of microplastics with freshwater biota. In: Wagner M, Lambert S (eds) Freshwater microplastics: emerging environmental contaminants? Springer Nature, Heidelberg. doi:10.1007/978-3-319-61615-5_8 (in this volume)

51. Lönnstedt OM, Eklöv P (2016) Environmentally relevant concentrations of microplastic particles influence larval fish ecology. Science 352:1213-1216

52. Dris R, Gasperi J, Rocher V, Saad M, Renault N, Tassin B (2015) Microplastic contamination in an urban area: a case study in Greater Paris. Environ Chem 12:592-599

53. Mani T, Hauk A, Walter U, Burkhardt-Holm P (2015) Microplastics profile along the Rhine river. Sci Rep 5:17988

54. Free CM, Jensen OP, Mason SA, Eriksen M, Williamson NJ, Boldgiv B (2014) High-levels of microplastic pollution in a large, remote, mountain lake. Mar Pollut Bull 85:156-163

55. McCormick A, Hoellein TJ, Mason SA, Schluep J, Kelly JJ (2014) Microplastic is an abundant and distinct microbial habitat in an urban river. Environ Sci Technol 48:11863-11871

56. Zbyszewski M, Corcoran P (2011) Distribution and degradation of fresh water plastic particles along the beaches of Lake Huron, Canada. Water Air Soil Pollut 220:365-372

57. Eriksen M, Mason S, Wilson S, Box C, Zellers A, Edwards W, Farley H, Amato S (2013) Microplastic pollution in the surface waters of the Laurentian Great Lakes. Mar Pollut Bull $77: 177-182$

58. Klein S, Dimzon IK, Eubeler J, Knepper TP (2017) Analysis, occurrence, and degradation of microplastics in the aqueous environment. In: Wagner M, Lambert S (eds) Freshwater microplastics: emerging environmental contaminants? Springer, Heidelberg. doi:10.1007/ 978-3-319-61615-5_3 (in this volume)

59. Dris R, Gasperi J, Tassin B (2017) Sources and fate of microplastics in urban areas: a focus on Paris Megacity. In: Wagner M, Lambert S (eds) Freshwater microplastics: emerging environmental contaminants? Springer, Heidelberg. doi:10.1007/978-3-319-61615-5_4 (in this volume)

60. Barnes DKA, Galgani F, Thompson RC, Barlaz M (2009) Accumulation and fragmentation of plastic debris in global environments. Philos Trans R Soc B 364:1985-1998

61. Verschoor AJ (2015) Towards a definition of microplastics. Considerations for the specification of physico-chemical properties. RIVM Letter report 2015-0116

62. JRC - Joint Research Centre of the European Commission (2013) MSDF Technical Subgroup on Marine Litter. Guidance on Monitoring of Marine Litter in European Seas. A guidance 
document within the Common Implementation Strategy for the Marine Strategy Framework Directive. Report No. EUR 26113 EN

63. Arthur C, Baker J and Bamford H 2009. Proceedings of the International Research Workshop on the Occurrence, Effects and Fate of Microplastic Marine Debris. 9-11 Sep 2008. NOAA Technical Memorandum NOS-OR\&R-30

64. EU (2011) Commission Recommendation of 18 October 2011 on the definition of nanomaterial (2011/696/EU). http://eur-lex.europa.eu. Retrieved 13 Nov 2016

65. Miklos D, Obermaier N, Jekel M (2016) Mikroplastik: Entwicklung eines Umweltbewertungskonzepts - Erste Überlegungen zur Relevanz von synthetischen Polymeren in der Umwelt. UBA Texte 32/2016. ISSN 1862-4804

66. Lambert S, Scherer C, Wagner M (2017) Ecotoxicity testing of microplastics: considering the heterogeneity of physicochemical properties. Integr Environ Assess Manag 13:470. doi:10. 1002/ieam.1901

67. OECD (2016) Environmental policy tools and evaluation. http://www.oecd.org/env/toolsevaluation/. Retrieved 28 Nov 2016

68. OECD (2001) Sustainable Development: Critical Issues. Paris, France

69. Essel, R., Engel, L., Carus, M., Ahrens, R.H. (2015) Sources of microplastics relevant to marine protection in Germany. UBA Texte 64/2015. Umweltbundesamt. Dessau-Roßlau, Germany. http://www.umweltbundesamt.de/publikationen/sources-of-microplastics-relevantto-marine

70. Lassen C, Hansen SF, Magnusson K, Hartmann NB, Rehne Jensen P, Nielsen TG, Brinch A (2015) Microplastics: occurrence, effects and sources of releases to the environment in Denmark. Danish Environmental Protection Agency, Copenhagen K

71. Norén F (2007) Small plastic particles in Coastal Swedish waters. KIMO, Sweden

72. Rist SE, Hartmann NB (2017) Aquatic ecotoxicity of microplastics and nanoplastics: lessons learned from engineered nanomaterials. In: Wagner M, Lambert S (eds) Freshwater microplastics: emerging environmental contaminants? Springer, Heidelberg. doi:10.1007/ 978-3-319-61615-5_2 (in this volume)

Open Access This chapter is licensed under the terms of the Creative Commons Attribution 4.0 International License (http://creativecommons.org/licenses/by/4.0/), which permits use, sharing, adaptation, distribution and reproduction in any medium or format, as long as you give appropriate credit to the original author(s) and the source, provide a link to the Creative Commons license and indicate if changes were made.

The images or other third party material in this chapter are included in the chapter's Creative Commons license, unless indicated otherwise in a credit line to the material. If material is not included in the chapter's Creative Commons license and your intended use is not permitted by statutory regulation or exceeds the permitted use, you will need to obtain permission directly from the copyright holder.

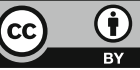

